Monatsschrift f. Geburtshülfe u. Gynäkologie 1918;47:1

\title{
Lieber Paul Ruge !
}

Wir übergeben Dir als Angebinde zur Feier Deines 70. Geburts-tages diese Festschrift. Sie soil Dir der sichtbare Ausdruck sein der Anerkennung und Freundschaft, welche Dir gynäkologische Fachgenossen, Freunde und weite Kreise nicbt nur in der Kollegen-schaft Berlins entgegenbringen. Mehrere unter diesen sind nur durch dringlichste Aufgaben dieser Zeit da von abgehalten word en, sich uns anzuschließen.

Du bist das Vorbild des Arztes, der seine voile Kraft in großem Wirkungskreis vorwiegend der geburtshülflich-gynäkologischen Be-tätigung widmet. Dabei hast Du Dir das in Deiner Lehrzeit unter Rudolf Virchow und Eduard Martin nachhaltig entwickelte und literarisch ausgiebig betätigte Verlangen wacherhalten, die fort-schreitende wissenschaftliche Forschung mitarbeitend zu verfolgen. Seit Jahrzehnten leistest Du autoritative Arbeit auf dem so be-deutungsvollen Gebiet der forensischen Frajienheilkunde.

Mögen Dir noch lange Jahre dieser segensreichen Arbeit be-schieden sein!

Fürbringer. A. Martin. G. Ruge I. Georg Ruge. G. Ruge II.

Monatsschrift f. GeburtsbüUe u. Gynäkologie. Bd. XLVII. Heft 1.

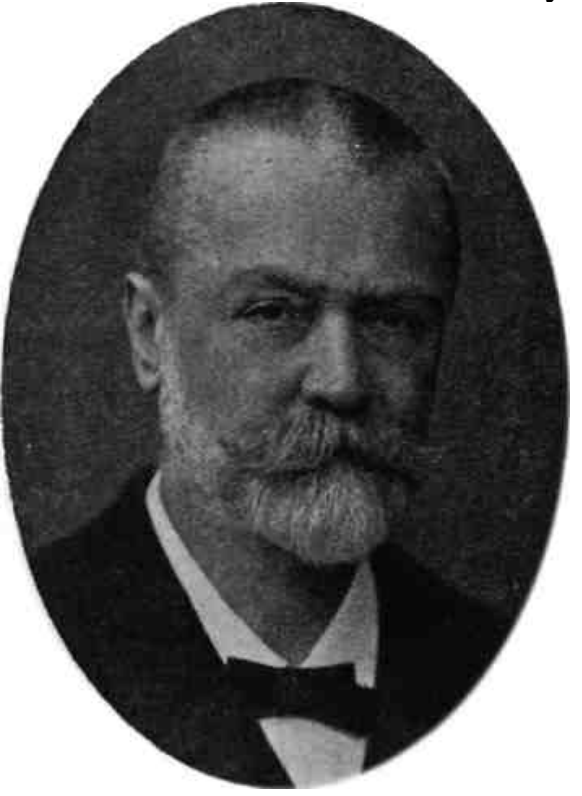

